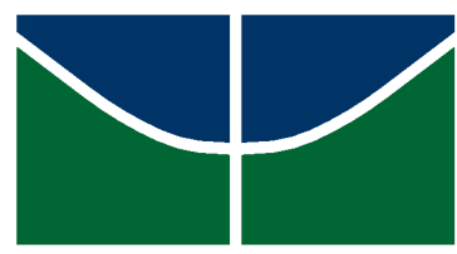

Universidade de Brasília

Faculdade de Ciências da Saúde

Departamento de Enfermagem

FRÉDSON RAFAEL PESSOA DE SOUZA

ASPECTOS DIFICULTADORES NA PREVENÇÃO DO HIV/AIDS EM ADOLESCENTES NO BRASIL: REVISÃO INTEGRATIVA 
FRÉDSON RAFAEL PESSOA DE SOUZA

\title{
ASPECTOS DIFICULTADORES NA PREVENÇÃO DO HIV/AIDS EM ADOLESCENTES NO BRASIL: REVISÃO INTEGRATIVA
}

\begin{abstract}
Trabalho de Conclusão de Curso apresentado ao curso de Enfermagem da Universidade de Brasília, Faculdade de Ciências da Saúde, Campus Darcy Ribeiro como requisito para obtenção parcial de Grau de Bacharel em Enfermagem.
\end{abstract}

Orientador: Prof. Dr. Pedro Sadi Monteiro 


\section{ASPECTOS DIFICULTADORES NA PREVENÇÃO DO HIV/AIDS EM ADOLESCENTES NO BRASIL: REVISÃO INTEGRATIVA}

Trabalho de Conclusão de Curso apresentado ao curso de Enfermagem da Universidade de Brasília, Faculdade de Ciências da Saúde, Campus Darcy Ribeiro como requisito para obtenção parcial de Grau de Bacharel em Enfermagem.

Aprovado em: ............................

Banca examinadora

Dr. Pedro Sadi Monteiro - FS/UnB

(Orientador)

Dra. Simone Roque Mazoni - FS/UnB

(Membro)

Dra. Valéria Bertonha Machado - FS/UnB

(Membro)

Dra. Thatianny Tanferri de Brito Paranaguá - FS/UnB

(Suplente) 
Ao DEUS do impossível, por estar sempre presente em minha vida e pelo meu tesouro imensurável: meus avós.

Aos meus pais, onde aprendi qual a maior grandeza do ser humano: o perdão.

E a todos que direta ou indiretamente contribuíram no percurso do meu caminho. 


\section{RESUMO}

SOUZA, F.R.P. Aspectos dificultadores na prevenção do HIV/AIDS em adolescentes no Brasil: revisão integrativa. 2018. Trabalho de Conclusão de Curso (Graduação) - Departamento de Enfermagem, Faculdade de Ciências da Saúde, Universidade de Brasília, Brasília, 2018.

Nos casos notificados no Sistema de Informação de Agravos de Notificação (SINAN) até o ano de 2016 e no Sistema de Informação Sobre Mortalidade (SIM) de 2000 até 2015 verifica-se tendência de queda de detecção no número de infectados por HIV, exceto para a faixa etária de 15 a 19 anos. Esse estudo é uma revisão integrativa realizada com publicações que abordam as dificuldades na prevenção do HIV/AIDS em adolescentes no Brasil. O objetivo do estudo foi conhecer por meio da análise de publicações científicas os aspectos que possam estar associados à prevenção da AIDS em adolescentes no Brasil no período que compreende os anos de 2012 a 2016. O método de revisão possibilitou a inclusão simultânea dos aspectos e a análise para atender mais plenamente a esse fenômeno de preocupação. Foram selecionados 13 artigos após as cinco etapas estruturantes dessa revisão. Na literatura revisada foram identificados um total de dezoito aspectos que os autores apontam como dificuldades enfrentadas durante a prevenção do HIV/AIDS para os adolescentes. Os aspectos são: educação, conhecimento, preservativo, prevenção, vulnerabilidade, autonomia, investimento, início precoce da vida sexual, determinantes sociais, acesso ao SUS, questões socioeconômicas, integralidade, violência doméstica, álcool e drogas, cultura e gênero, nível de escolaridade, exploração sexual e diálogo. A educação foi abordada em 11 artigos $(84,6 \%)$ o que representa quase totalidade da literatura da revisão, enquanto a exploração sexual continua sendo um aspecto pouco discutido aparecendo em apenas um único artigo, o que significa 7,6\% da literatura revisada. A prevenção é um aspecto pouco discutido na literatura, a palavra prevenção é apenas colocada em seu sentido estrito. Esse estudo tenta trazer uma pequena contribuição para a temática e sugere a necessidade de (re)pensar o modelo de prevenção para HIV/AIDS em adolescentes. Pensar a prevenção do HIV/AIDS para adolescentes no Brasil também significa identificar quais aspectos dificultam essa prática. A promoção e prevenção da saúde a esse grupo é uma tarefa ampla e complexa que exige uma articulação do setor saúde com os demais setores da sociedade.

Palavras-chaves: HIV, adolescentes, prevenção, aspectos dificultadores. 


\section{LISTA DE TABELAS}

TABELA 1 - Apresentação da síntese de artigos incluídos na revisão

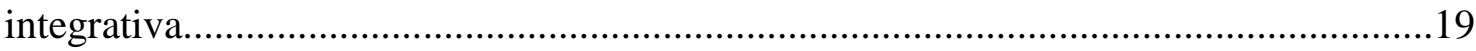




\section{LISTA DE FIGURAS}

FIGURA 1 - Fluxograma identificação, seleção e inclusão dos artigos para revisão

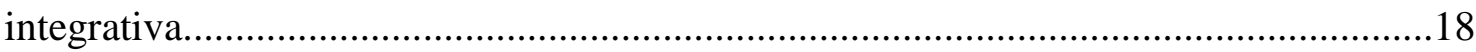

FIGURA 2 - Aspectos dificultadores encontrados na literatura...................................21 


\section{SUMÁRIO}

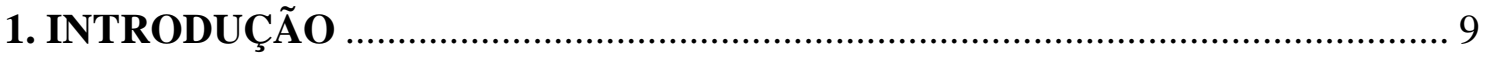

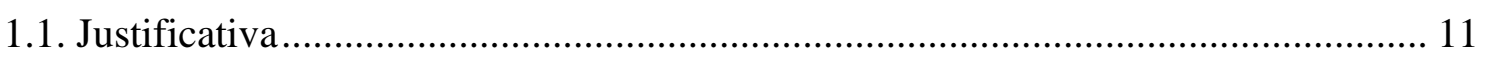

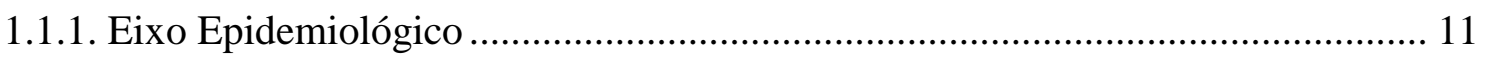

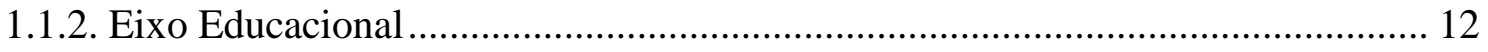

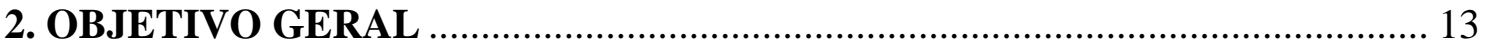

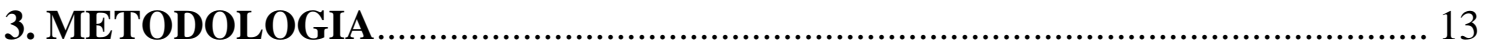

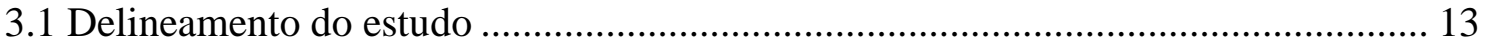

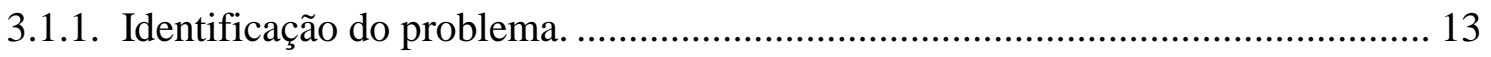

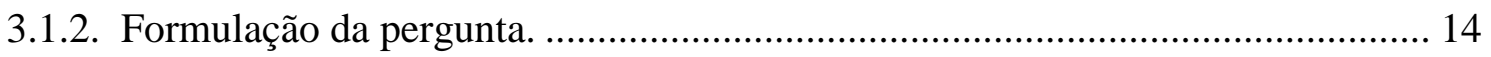

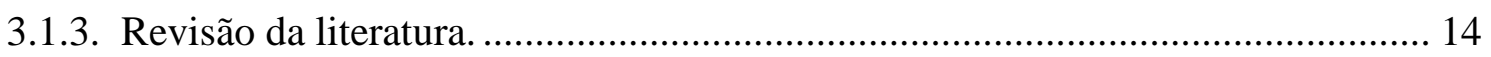

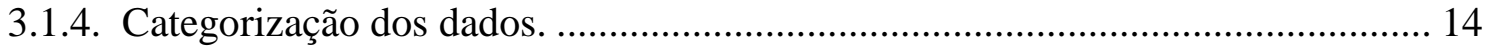

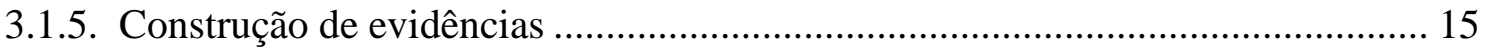

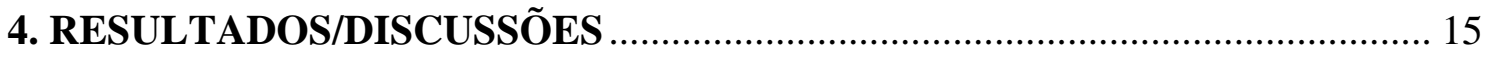

5. CONCLUSÃO

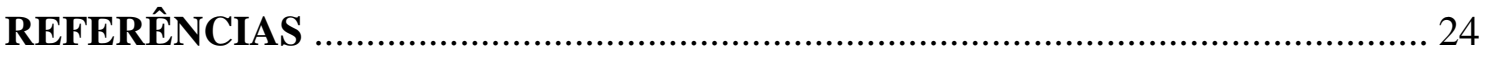

APÊNDICES 






\section{INTRODUÇÃO}

A adolescência é a fase da vida caracterizada por mudanças, pela busca da identidade, época em que o ser humano vivencia novas maneiras de interagir e se relacionar. É uma fase ímpar do desenvolvimento humano imersa em um contexto com características biopsíquicas, emocionais, intelectuais e culturais (ROEHRS, 2010). Adolescência é um fenômeno singular e plural (SILVA, 2015). Etapa da vida em que o ser humano procura desenvolver sua identidade ligando-a a sentimentos, desejos e necessidades. É nesse período que se tem início à organização sexual e onde a identidade sexual torna-se importante. Para muitos adolescentes, é comum nesse período da vida, o início da atividade sexual (RIBEIRO, 2015).

A Organização Mundial da Saúde (OMS) estabelece que adolescentes são jovens entre 10 e 19 anos de idade, fase de crescimento e desenvolvimento humano que acontece após a infância e antes da vida adulta. Dentro dessa faixa etária as causas de óbitos mais comuns estão relacionadas a acidentes, suicídio, violência, complicações na gravidez e doenças evitáveis e tratáveis (WHO, 2017). Muitas patologias graves da vida adulta têm inicio na adolescência, visto que essas são as principais causas da prevalência e/ou morte prematura de adolescentes, como por exemplo, o consumo do tabaco e infecções sexualmente transmissíveis, em especial o Vírus da Imunodeficiência Humana (WHO, 2017).

Sabe-se que o principal foco de ação do HIV/AIDS é o sistema imunológico do ser humano. Quando o indivíduo é infectado as células do sistema imune têm suas respectivas funções alteradas ou canceladas. A infecção por sua vez provoca de maneira progressiva a perda da função e deterioração do sistema imunológico o que causa a "imunodeficiência". Em seguida as células de defesa do organismo deixam de executar a sua função na luta contra infecções e doenças (WHO, 2017). Na história natural da doença ocorre a depleção dos linfócitos T CD4+ o que gera a queda da imunidade e a predisposição para doenças oportunistas graves (SOUSA, 2014).

A AIDS/SIDA (Síndrome da Imunodeficiência Adquirida) é definida quando se tem a presença de mais de 20 infecções oportunistas ou relacionadas com o HIV. As formas de transmissão do HIV conhecidas são através da relação sexual vaginal, anal ou oral, sexo com pessoa infectada, transfusão de sangue contaminado ou partilha de agulha, seringas ou instrumentos perfuro cortantes e de mãe para o filho durante a gestação, parto ou amamentação (WHO, 2017). A infecção pelo Vírus da Imunodeficiência Humana e a 
Síndrome da Imunodeficiência Adquirida é um problema de saúde pública em nível mundial (CHEHTER, 2014).

O HIV/AIDS em adolescentes na esfera global traduzida em números é preocupante. Mais de dois milhões de adolescentes entre 10 e 19 anos de idade estão infectados pelo HIV/AIDS, essa cifra é alarmante e por se tratar de um grupo vulnerável esse número poderá aumentar em um curto período. As taxas de mortalidade de adolescentes com HIV/AIDS não estão diminuindo na mesma extensão em relação aos demais grupos da população. Se fizermos uma breve análise comparativa desses números poderemos imaginar a dimensão com que os adolescentes estão se infectando com o HIV/AIDS. A OMS revela que no período de 2005 a 2012 as mortes relacionadas com HIV/AIDS caíram 30\% e em adolescentes as causas de morte relacionadas ao HIV/AIDS nesse mesmo período aumentaram quase o dobro, chegando a $50 \%$ (WHO, 2013).

Esses dados deixam claros que esse grupo "segue na contra mão" quando comparados com os demais grupos populacionais. No Brasil a taxa de detecção segue de acordo com o perfil mundial. De acordo com o Boletim Epidemiológico HIV/AIDS 2016, elaborado pelo Ministério da Saúde os números apontam um aumento da taxa de detecção de AIDS em adolescentes.

O que pode ser observado nos casos notificados no Sistema de Informação de Agravos de Notificação (SINAN) até 30/06/2016 e no Sistema de Informação Sobre Mortalidade (SIM) de 2000 até 2015 é uma tendência de queda de detecção no número de casos, exceto para a faixa etária de 15 a 19 anos (BRASIL, 2016). Esses números é a principal fonte que direciona essa pesquisa uma vez que a notificação de casos aumenta no decorrer dos anos para adolescentes.

O Boletim Epidemiológico do Ministério da Saúde aborda os números separadamente de acordo com faixa etária e sexo e traduz que entre os homens, de modo exclusivo entre 15 e 19 anos de idade, no decorrer de 2006 a 2015 a taxa triplicou (de 2,4 para 6,9 casos/100 mil hab.). No que se refere às mulheres de modo geral o esboço epidemiológico apresenta uma queda em quase todas as faixas de idade, com exceção, para mulheres adolescentes entre 15 e 19 anos de idade que teve uma cifra de 12,9\% de aumento de 2006 a 2015 (BRASIL, 2016). Entre os sexos a razão varia em acordo com as faixas etárias, o que pode ser visto é a tendência de aumento entre adolescentes de 13 a 19 anos. Na razão de sexos observa-se 17 casos em homens para cada 10 casos em mulheres, em 2015 houve um percentual de $62 \%$ de casos a mais para homens do que para mulheres (BRASIL, 2016). 


\subsection{Justificativa}

A temática HIV/AIDS é um assunto amplo e que merece ser abordado em um ângulo mais abrangente, seguindo o raciocínio, apresentamos como justificativa central dois eixos estruturais que apresentam relação com a prevenção do HIV/AIDS em adolescentes brasileiros. De uma maneira resumida serão abordados pontos que permitirão analisar a temática não apenas com uma visão unidirecional mais em um contexto multidirecional que influenciam na prevenção de casos de HIV/AIDS em adolescentes no Brasil. São os dois eixos: epidemiológico e educacional, em cada eixo serão levantados dados, informações e contextos pertinentes que ajudem a discutir a temática.

\subsubsection{Eixo Epidemiológico}

Pelo fato do HIV/AIDS ser um dos maiores problemas de saúde pública mundial, o aumento do número de casos em adolescentes é preocupante. Esses números, já mencionados, permitem fazer uma projeção, de que em poucos anos teremos um maior número de portadores na vida adulta. Como sabemos o HIV/AIDS é uma doença sem cura e por isso permite projetar que sendo prevalente na fase da adolescência essa prevalência sofrerá uma transição para a fase adulta. Nessa faixa de idade (entre 10 e 19 anos) em muitos povos e culturas do mundo, incluindo o Brasil, inicia-se a atividade sexual e reprodutiva. Estudo realizado por Ribeiro (2015) mostra a sexarca entre 12 a 14 anos de idade, assim como o estudo de Patias e Dias (2014) que aponta a sexarca aos 14,54 anos.

A OMS reconhece que adolescentes têm um início prematuro da atividade sexual e que o risco da infecção pelo HIV está relacionado com a idade de início da relação sexual e incentiva o atraso da atividade do início sexual e a abstinência. Dentro dessa conjuntura pode ser observado que temos nossos adolescentes expostos a grandes formas de infecção e transmissão do HIV, como por exemplo, através do sexo e consequentemente a transmissão vertical. Nesse eixo ainda permite uma maior discussão, pois o início precoce da atividade sexual está ligado a inúmeros fatores como: sociais, culturais, tecnológicos, o advento da internet, a mídia, a cultura do machismo, a competitividade, a sexualidade, o casamento e as questões de gênero. Todos esses fatores influenciam o início da atividade sexual dos adolescentes e um consequente aumento do número de infectados pelo HIV nessa faixa etária. 


\subsubsection{Eixo Educacional}

O grau de escolaridade é um fator fundamental a ser considerado quando analisados os determinantes da saúde que cercam os adolescentes e durante a abordagem desses adolescentes para desenvolver a promoção, prevenção e recuperação da saúde (RIBEIRO, 2015). Várias condições de saúde podem ser influenciadas diretamente pelo nível de escolaridade. Nesse cenário fica claro que o baixo nível escolar afeta de maneira negativa o modo de pensar o autocuidado em sua saúde e a necessidade de atuar em contextos coletivos de saúde (FONSECA, 2007).

Dentre os vários problemas que influenciam o nível escolar dos adolescentes, temse, por exemplo: a dependência química dos pais, violência doméstica, abuso sexual por pais, orfandade e exploração no trabalho. Essas são uma das principais causas dos adolescentes abandonarem seus lares e consequentemente a essas causas, o abandono à escola (RIBEIRO, 2015).

Por ser uma fase da vida considerada complexa, a adolescência é permeada por um sentimento de invulnerabilidade, uma autoconfiança exacerbada, características essas que influencia nas tomadas de decisões dos adolescentes (RODRIGUES, 2016). O pensamento do "'eu posso tudo", atrelado ao despertar do desejo sexual, move com as emoções, sensações e sentimentos que culmina em relações sexuais desprotegidas o que torna o adolescente vulnerável as DST's e HIV/AIDS. Essa vulnerabilidade à DST e a AIDS/HIV decorre de vários fatores, como a impulsividade, idade da primeira relação sexual, egocentrismo e principalmente a falta de informação (RIBEIRO, 2015).

A família e a escola também são fundamentais uma vez que ambas influenciam na saúde e no bem estar dos adolescentes. A família bem como sua composição e o monitoramento dos pais podem contribuir negativamente para o comportamento sexual. $\mathrm{Na}$ escola quando não recebem informações sobre saúde reprodutiva e sexual é um fato que contribui para aumentar as chances desses adolescentes terem relações sexuais desprotegidas. Estudo mostra que informações acerca da gravidez na adolescência e DST devem ser divulgadas cedo por serem muito valiosas para alunos que iniciam as atividades sexuais precocemente, antes dos 13 anos de idade (OLIVEIRA, 2013).

Vários estudos afirmam que a idade da sexarca e menarca estão diminuindo em nível mundial, e concomitantemente relações sexuais de risco o que potencializa a decorrente gravidez na adolescência e infecção por DST (CERQUEIRA-SANTOS, 2010; RIBEIRO, 2015). Esse fenômeno está atingindo todas as classes sociais e tem uma forte relação com 
pobreza e baixa escolaridade onde os adolescentes mais afetados são os que estão em condições sociais mais desfavorecidas.

\section{OBJETIVO GERAL}

Conhecer por meio da análise de publicações científicas os aspectos associados à prevenção do HIV/AIDS em adolescentes no Brasil no período que compreende os anos de 2012 a 2016.

\section{METODOLOGIA}

Esse é um estudo de revisão integrativa. No entanto é cabível mencionar que existem similaridades nas etapas de desenvolvimento de uma revisão integrativa (SOARES, 2014). Diferentes autores adotam maneiras distintas de subdivisão da revisão integrativa, com pequenas modificações (MENDES, 2009). Assim a metodologia que será adotada para o desenvolvimento desse trabalho é conforme a proposta de autoras americanas, Whittenore e Knalf, 2005.

\subsection{Delineamento do estudo}

A revisão integrativa é considerada o tipo mais amplo de revisão de pesquisa. É um método que possibilita a inclusão simultânea de experiências, trata-se da análise de pesquisas experimentais e não experimentais para que se possa atender mais plenamente um fenômeno de preocupação. Além disso, as revisões integrativas incorporam uma ampla gama de propósitos: definir conceitos, revisar teorias, revisar evidências e analisar metodologias (WHITTEMORE, 2005). É um estudo que inter-relaciona resultados de estudos anteriores, de forma crítica, para produzir novo conhecimento integrado (TORRACO, 2005). É um estudo de revisão integrativa composto de cinco etapas, nos próximos itens seguem as etapas que foram adotadas nesse estudo:

3.1.1. Identificação do problema. 
'’O aumento do número de adolescentes infectados pelo HIV no Brasil'’. Problema que se faz presente nessa faixa etária, aliás a única que mostra aumento em relação ao número de infectados pelo HIV (BRASIL, 2016).

\subsubsection{Formulação da pergunta.}

' Quais os principais aspectos dificultadores na prevenção da infecção por HIV em adolescentes brasileiros? Essa foi a questão norteadora desse estudo e que embasou as demais etapas metodológicas. As duas primeiras etapas foram abordadas, revisadas e discutidas anteriormente durante a introdução e justificativa do trabalho.

\subsubsection{Revisão da literatura.}

Como critérios de inclusão foram utilizados: artigos que abordassem a problemática no Brasil, a faixa etária (adolescentes de 10 a 19 anos), que atendem aos descritores: 'HIV', "HIV em adolescentes" e " prevenção"; artigos que retratem a temática relacionada ao Brasil, artigos indexados nos bancos de dados no período que foi delimitado dentro da pesquisa de 2012/2016 e artigos que estejam publicados em espanhol, inglês e português. Os critérios de exclusão foram artigos que estavam incompletos na íntegra.

Para o levantamento bibliográfico foi utilizada como ferramenta a Internet onde foram consultados os bancos de dados: Literatura Latino-Americana em Ciências da Saúde (LILACS) onde pode ser acessado on line através do BIREME (Centro Latino Americano e do Caribe de Informações em Ciências da Saúde), Medical Literature Analysis and Retrieval Sistem on-line (Medline) que poderá ser acessado através do PUBMED, Scielo Scientific Electronic Library Online (SCIELO) e base de dados do Ministério da Saúde (MS).

\subsubsection{Categorização dos dados.}

Os dados estão ordenados e codificados de acordo com ano de publicação, categorizados em forma de aspectos e resumidos em uma conclusão unificada e integrada acerca do tema. Nessa etapa um exame minucioso e imparcial juntamente com uma síntese foi realizado. Para coleta de dados utilizou-se a tabela matriz (URSI, 2006) que permitiu unir e compilar dados de diferentes artigos. Os dados foram extraídos dos artigos e organizados na 
tabela matriz e isso facilitou a distinção entre ano de publicação, temas, autores e resultados/conclusões. Em seguida esses dados foram comparados item por item para que variáveis semelhantes pudessem ser agrupadas e categorizadas de acordo com suas correlações (WHITTEMORE, 2005). A categorização deu-se em forma de aspectos e esboçada em gráfico (FIGURA 2). Para fins didáticos foi utilizado um quadro sinóptico que contempla os seguintes itens: aspectos, código do artigo e percentual (apêndice 1) .

\subsubsection{Construção de evidências}

Uma síntese foi elaborada abordando os aspectos identificados durante a revisão e correlacionando-os seguindo uma linha dentro da temática o que possibilitou a formulação de evidência do fenômeno e resposta para a pergunta norteadora do estudo: 'Quais os principais aspectos dificultadores na prevenção da infecção por HIV/AIDS em adolescentes brasileiros? De maneira descritiva os achados estão discutidos, sejam quantitativos e/ou qualitativos, contemplando o tema e inter-relacionados entre si completando assim o processo de revisão (WHITTEMORE, 2005).

\section{RESULTADOS/DISCUSSÕES}

A busca eletrônica em base de dados resultou em 5.885 referências identificadas. Dessas 2.975 foram eliminadas por estarem fora do período que compreende a revisão, entre os anos 2012-2016, e que não abordaram a temática. Nesta etapa 13 artigos foram elegíveis após análise dos critérios de inclusão. As referências selecionadas foram publicadas entre 2012 e 2016, tendo sido duas publicadas em 2012, quatro em 2013, duas em 2014, quatro em 2015 e apenas uma em 2016. O que se observa é que as publicações que tratam sobre a prevenção do HIV/AIDS em adolescentes é um número pequeno e diminuiu, isso pode ser considerado preocupante, tendo em vista a gravidade do HIV/AIDS e o aumento de casos em adolescentes no Brasil.

A coleta de dados ocorreu entre os meses de julho e outubro de 2017 por meio de processamento eletrônico em bases cientificas de dados via internet. O processamento e interpretação dos dados foram feitos nos meses de novembro de 2017 a fevereiro de 2018 e a elaboração do trabalho com os resultados deu-se no período de março de 2018 a junho de 2018. 
FIGURA 1 - Fluxograma de identificação, seleção e inclusão dos artigos para revisão integrativa.

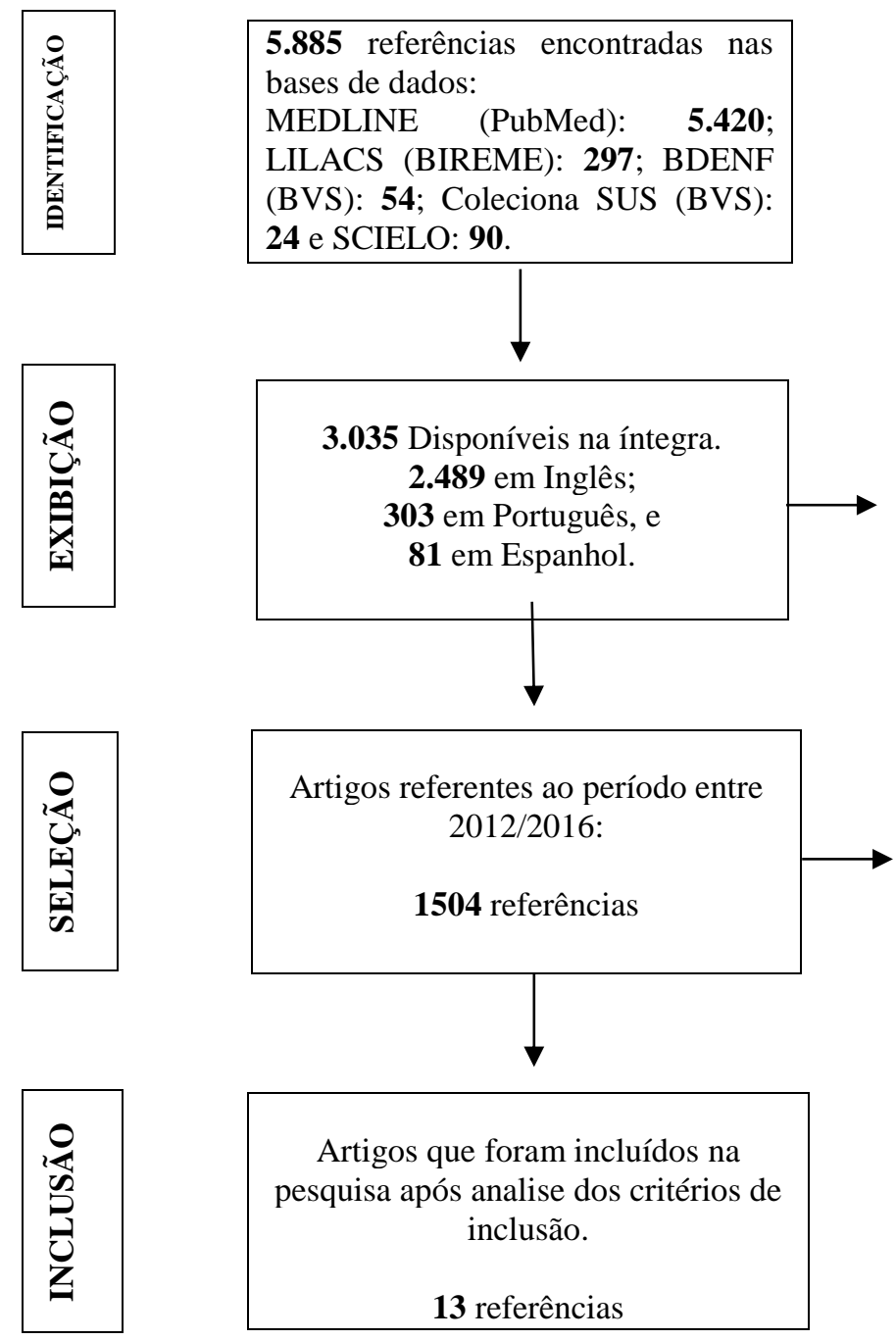

Excluídas: 162 Referências em outros idiomas.

Artigos que tragam a temática: para ''adolescentes no Brasil'".

60 referências

As referências que foram incluídas para fins de revisão integrativa tratam a temática para adolescentes especificamente no Brasil. Na literatura revisada foram identificados um total de dezoito aspectos que os autores apontam como dificuldades enfrentadas durante a prevenção do HIV/AIDS para os adolescentes. Os aspectos são: educação, conhecimento, preservativo, prevenção, vulnerabilidade, autonomia, investimento, início precoce da vida sexual, determinantes sociais, acesso ao SUS, questões socioeconômicas, integralidade, violência doméstica, álcool e drogas, cultura e gênero, nível de escolaridade, exploração sexual e diálogo.

O referencial teórico para ser apresentado de uma maneira mais sintética foi esboçado em uma tabela matriz. Nessa tabela os artigos ganharam um código e em seguida foram descritos: o ano de publicação, nome do artigo, autores e resultados/conclusões. Os 
códigos dos artigos serão utilizados durante a discussão como referência para os argumentos extraídos dos seus respectivos artigos.

Tabela 1 - Apresentação da síntese de artigos incluídos na revisão integrativa.

\begin{tabular}{|c|c|c|c|c|}
\hline Código & $\begin{array}{c}\text { Ano de } \\
\text { publicação }\end{array}$ & Título do Artigo & Autores & Resultados/Conclusões \\
\hline A01 & 2012 & 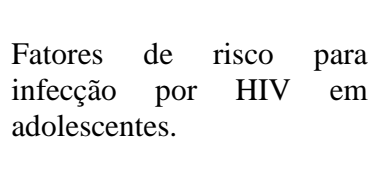 & Araújo, T.M.E. et all. & $\begin{array}{c}\text { Educação, Conhecimento, } \\
\text { Preservativo, Vulnerabilidade, } \\
\text { Investimento, Precoce, } \\
\text { Socioeconômico, Integralidade, } \\
\text { Álcool e Drogas. }\end{array}$ \\
\hline A02 & 2012 & $\begin{array}{l}\text { Cultura masculina e } \\
\text { religiosidade na prevenção } \\
\text { das DST/HIV/AIDS em } \\
\text { adolescentes. }\end{array}$ & $\begin{array}{l}\text { Ferreira, A.G.N. et } \\
\text { all. }\end{array}$ & $\begin{array}{c}\text { Educação, Preservativo, } \\
\text { Autonomia, Violência } \\
\text { Doméstica, Cultura e Gênero. }\end{array}$ \\
\hline A03 & 2013 & $\begin{array}{l}\text { The gap between } \\
\text { knowledge on HIV/AIDS } \\
\text { and sexual behavior: a study } \\
\text { of teenagers in Vespasiano, } \\
\text { Minas Gerais State, Brazil. }\end{array}$ & Moura, L.R. et all. & $\begin{array}{l}\text { Educação, Conhecimento, } \\
\text { Preservativo, Precoce e } \\
\text { Determinantes. } \\
\text { Sociais. }\end{array}$ \\
\hline A04 & 2013 & $\begin{array}{l}\text { Vulnerabilidade de } \\
\text { adolescentes escolares às } \\
\text { DST/HIV, em Imperatriz - } \\
\text { Maranhão. }\end{array}$ & Costa, A.C.P.J. et all. & $\begin{array}{c}\text { Educação, Conhecimento, } \\
\text { Preservativo, Vulnerabilidade, } \\
\text { Prevenção e Determinantes } \\
\text { Sociais. }\end{array}$ \\
\hline A05 & 2013 & $\begin{array}{l}\text { Epidemia de HIV/AIDS em } \\
\text { adolescentes no Brasil e na } \\
\text { França: semelhanças e } \\
\text { diferenças. }\end{array}$ & Taquette, S.R. et all. & $\begin{array}{c}\text { Educação, Conhecimento, } \\
\text { Preservativo, Vulnerabilidade, } \\
\text { Investimento, Acesso ao SUS e } \\
\text { Escolaridade. }\end{array}$ \\
\hline
\end{tabular}




\begin{tabular}{|c|c|c|c|c|}
\hline Código & $\begin{array}{c}\text { Ano de } \\
\text { publicação }\end{array}$ & Título do Artigo & Autores & Resultados/Conclusões \\
\hline A06 & 2013 & $\begin{array}{lrr}\begin{array}{l}\text { Dialogando } \\
\text { adolescentes }\end{array} & \text { de } & \text { grupos } \\
\text { religiosos } & \text { sobre } & \text { HIV: } \\
\text { desafios } & \text { para } & \text { a } \\
\text { enfermagem. } & & \end{array}$ & Vieira, N.F.C. et all. & $\begin{array}{c}\text { Educação, Conhecimento, } \\
\text { Preservativo, Prevenção e } \\
\text { Diálogo. }\end{array}$ \\
\hline A07 & 2014 & $\begin{array}{l}\text { Conhecimentos e atitudes } \\
\text { de adolescentes de uma } \\
\text { escola pública sobre } \\
\text { transmissão sexual do HIV. }\end{array}$ & Chaves, A.C.P. et all. & $\begin{array}{l}\text { Educação, Conhecimento, } \\
\text { Prevenção e Precoce }\end{array}$ \\
\hline A08 & 2014 & $\begin{array}{l}\text { A vulnerabilidade ao HIV } \\
\text { em adolescentes: estudo } \\
\text { retrospectivo em um centro } \\
\text { de testagem } \\
\text { aconselhamento. }\end{array}$ & $\begin{array}{c}\text { Campos, C.G.A.P. et } \\
\text { all. }\end{array}$ & $\begin{array}{c}\text { Educação, Preservativo, } \\
\text { Vulnerabilidade, Prevenção, } \\
\text { Determinantes Sociais, Acesso ao } \\
\text { SUS, Violência Doméstica, } \\
\text { Álcool e Drogas e Escolaridade. }\end{array}$ \\
\hline A09 & 2015 & $\begin{array}{l}\text { O adolescente brasileiro e } \\
\text { as razões do não uso do } \\
\text { preservativo para prevenção } \\
\text { do HIV/AIDS. }\end{array}$ & Silva, A.F. et all. & $\begin{array}{c}\text { Educação, Conhecimento, } \\
\text { Investimento, Autonomia, } \\
\text { Socioeconômico, Cultura e } \\
\text { Gênero. }\end{array}$ \\
\hline A10 & 2015 & $\begin{array}{l}\text { Adolescentes } \\
\text { acolhimento provisório: } \\
\text { uma análise investigativa } \\
\text { sobre a vulnerabilidade ao } \\
\text { HIV. }\end{array}$ & Cavalcanti, L.J. et all. & $\begin{array}{c}\text { Educação, Conhecimento, } \\
\text { Preservativo, Acesso ao SUS e } \\
\text { Exploração Sexual. }\end{array}$ \\
\hline A11 & 2015 & $\begin{array}{l}\text { O pensamento complexo } \\
\text { subsidiando estratégias de } \\
\text { cuidados para a prevenção } \\
\text { das DST/AIDS na } \\
\text { adolescência. }\end{array}$ & Leite, J.L. et all. & Autonomia e Integralidade. \\
\hline A12 & 2015 & $\begin{array}{l}\text { Protagonismo de } \\
\text { adolescentes na prevenção } \\
\text { de doenças sexualmente } \\
\text { transmissíveis. }\end{array}$ & Gubert, F.A. et all. & $\begin{array}{l}\text { Educação, Conhecimento, } \\
\text { Preservativo e Autonomia. }\end{array}$ \\
\hline A13 & 2016 & 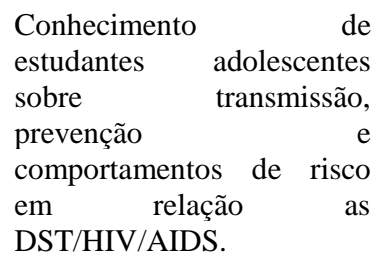 & Prado, C.C. et all. & $\begin{array}{l}\text { Conhecimento, Preservativo e } \\
\text { Prevenção. }\end{array}$ \\
\hline
\end{tabular}


Uma particularidade encontrada nessa revisão foi a discrepância de abordagem dos aspectos pelos autores em cada literatura. A educação foi abordada em 11 artigos (84,6\%) o que representa quase totalidade da literatura da revisão, enquanto a exploração sexual continua sendo um aspecto pouco discutido aparecendo em apenas um único artigo, o que significa 7,6\% da literatura revisada. Para melhor visualização e entendimento os aspectos identificados na literatura foram lançados em um gráfico. Esses aspectos levantados estão sendo apontados como as dificuldades encontradas durante a prevenção do HIV em adolescentes.

FIGURA 2 - Aspectos dificultadores encontrados na literatura

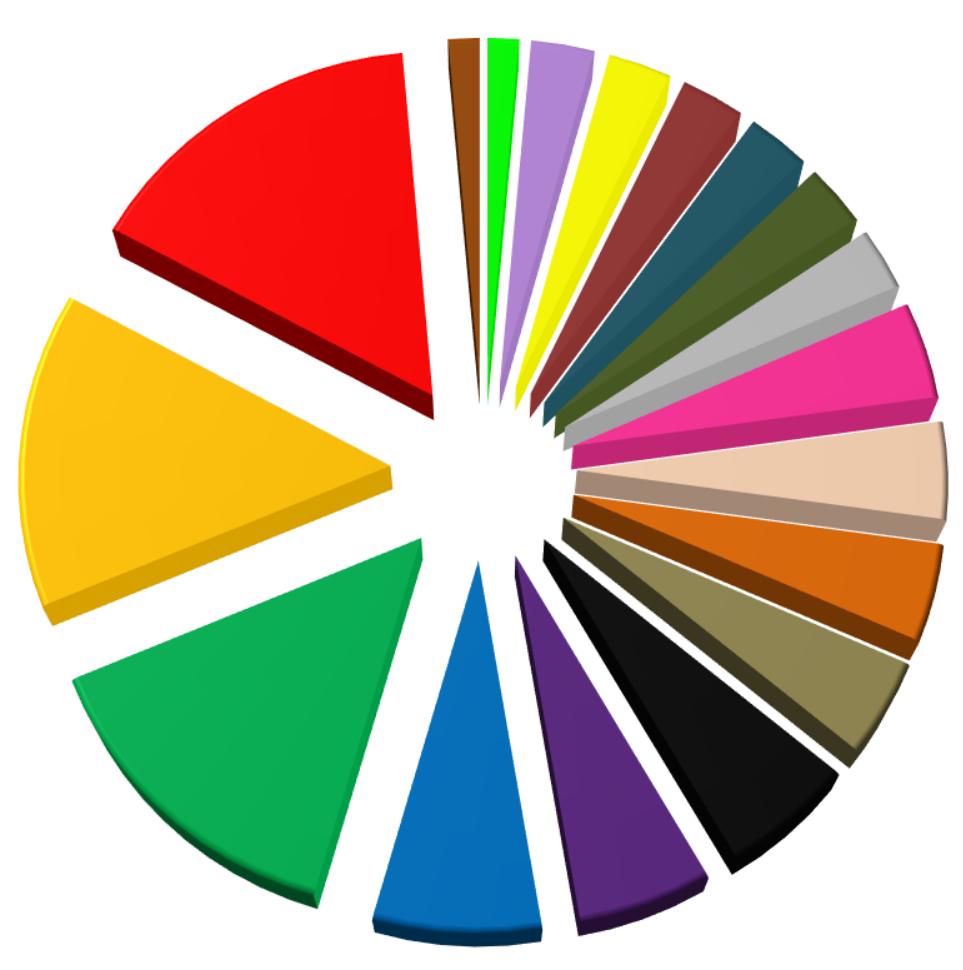

\author{
Exploração sexual \\ Escolaridade \\ 口Cultura e Gênero \\ Alcool e Drogas \\ ⿴囗十 Violência Doméstica \\ Integralidade \\ 【Socioeconômico \\ Acesso ao SUS \\ $\triangle$ Determinantes Sociais \\ 口Precoce \\ Investimento \\ autonomia \\ Q Vulnerabilidade \\ 口 Prevenção \\ 回Preservativo \\ \Conhecimento \\ Educação
}

O aspecto educação foi amplamente abordado pelos autores pelo fato da educação proporcionar medidas de ação e reflexão dos adolescentes sobre o tema e sua vulnerabilidade frente ao HIV/AIDS (A04). Além de possibilitar ambientes coletivos e interativos, a educação também favorece o desenvolvimento de campanhas criativas e educativas. A realidade em nosso país é que a discussão sobre a temática no meio educacional não ganhou força suficiente para provocar mudanças no perfil cultural dos adolescentes (A05). A literatura aponta para a importância da educação continuada, o que em tese justifica que os adolescentes 
precisam de uma educação efetiva e permanente para a aquisição de conhecimentos e habilidades (A07).

Propostas para a modificação da educação foram sugeridas, como exemplos: um novo enfoque na saúde sexual e reprodutiva nas escolas, no esclarecimento de questões de como exercer a sexualidade de maneira natural e livre de comportamentos de risco e preconceitos (A01). Devido a essas constatações é possível projetar que os horizontes da educação devem se expandir cada vez mais, abordando conhecimentos sempre de maior abrangência sobre adolescência e sexualidade proporcionando o aprimoramento de técnicas educacionais ainda mais adequadas e direcionadas para esse público (SAITO, 2000).

Outro aspecto identificado e muito abordado é o conhecimento (76,9\%), principalmente o conhecimento sobre o uso preservativo e da prevenção do vírus. É possível identificar que o que ocorre no Brasil é uma discussão vaga tratando desses três aspectos (conhecimento, preservativo e prevenção). Há uma real necessidade de medidas que abordem a orientação contínua sobre o uso do preservativo (A01). O conhecimento da causalidade e formas de transmissão do vírus persistem equivocadas pelos adolescentes e isso significa que eles possuem uma baixa percepção do risco de se infectarem (A10). Na realidade esse grupo ainda desconhece as possibilidades de transmissão através do sexo oral, transmissão vertical e do leite materno (A13). As abordagens sobre o tema ainda transitam de maneira superficial não havendo esclarecimentos sólidos relacionados à prevenção, que é abordada em 38,4\% dos artigos.

O que pode ser detectado nessa revisão é o desconhecimento das formas de transmissão e prevenção do HIV pelos adolescentes brasileiros, e é a insuficiência do conhecimento que acaba tornando esse público mais vulnerável à infecção (A07). A principal forma de prevenção é o preservativo, identificado em 76,9\% da literatura, mas, ainda ocorre uma baixa adesão ao seu uso pelo fato dos adolescentes associarem ao uso do preservativo à diminuição do prazer durante o ato sexual e nesse cenário é sugerido que se tenha uma maior conscientização por parte dos adolescentes para ampliarem o uso do preservativo (A04). Os costumes, as questões de gênero, a faixa etária e o nível escolar também influenciam no uso do preservativo (A05).

Esse é um grupo de alta vulnerabilidade às DST's, inclusive HIV/AIDS, pelo fato de um percentual significativo não fazerem uso do preservativo e iniciarem precocemente a vida sexual (A01). Outros fatores contribuem para essa vulnerabilidade, como o desconhecimento sobre o HIV desde as formas de contágio, o uso do preservativo, os fatores culturais, socioeconômicos e religiosos (A04). O que torna esses adolescentes cada vez mais 
vulneráveis é um número maior de fatores inter-relacionados entre si, como, por exemplo: a violência baseada em gênero, relação entre maternidade e pobreza e atendimento à saúde (A08). A literatura também aborda contextos que estes adolescentes estão expostos, como a homofobia, a desigualdade de gênero, a violência contra a mulher e a normatização do comportamento. Fato importante é que a normatização torna-se um paradoxo: de um lado a mídia com a erotização e do outro a sociedade que trata o sexo na adolescência como precoce e inadequado (A05). Esses fatores desenham as características do aspecto vulnerabilidade desses adolescentes e devem ser atentamente observados durante a promoção e prevenção da saúde desse grupo.

Seguindo essa linha, para contrapor a normatização do comportamento, o enfermeiro deve intervir com ações voltadas para a autonomia (30,7\%) do adolescente evolvendo estratégias contínuas e integradas em benefício da mudança do comportamento, assim possibilita ao adolescente tornar-se agente de transformação dessa realidade (A09). Essa transformação pode ser alcançada por meio de estratégias educativas emancipatórias o que permite construir novos saberes, novas práticas e novos sujeitos (A02). Para a prevenção da AIDS estão a construção e o exercício de sua autonomia, o adolescente é um ser singular que tem o papel de protagonista do cuidado de si (A11). A construção de uma identidade autônoma faz com que o adolescente assuma a responsabilidade de exercer a sua sexualidade, portanto tem que ser dado ao adolescente o poder de escolha para uma sexualidade saudável, natural e sem riscos.

O investimento é outro aspecto que a longo prazo pode ser usado para a mudança desse comportamento dos adolescentes e que pode ser um forte aliado na prevenção da AIDS, infelizmente a escassez de recursos e a falta de uma política pública sólida inviabiliza investimentos satisfatórios (A09). O investimento se faz necessário para a prevenção de doenças sexualmente transmissíveis na população de adolescentes, especialmente os de baixa renda, que devido às suas condições sociais acabam favorecendo a disseminação viral (A01). Receitas devem ser direcionadas para a melhoria e ampliação do acesso a serviços de saúde sexual e reprodutiva com ênfase no diagnóstico, tratamento, informações contraceptivas e insumos de prevenção, inclusive na qualidade do pré-natal (A05).

A ampliação do acesso, aspecto também encontrado durante a revisão, identificado em 23,07\% dos artigos. A literatura aponta que o Estatuto da Criança e do Adolescente deve ser preconizado, uma vez que este garante a legitimidade do adolescente permitindo seu acesso ao SUS sem necessidade do acompanhamento dos pais ou responsáveis. Esse aspecto é importante porque muitas vezes o atendimento a saúde é impossibilitado aos adolescentes 
pelo fato de não estarem acompanhados do responsável legal, isso acaba impedindo o aconselhamento, as orientações relacionadas à prática do sexo seguro e o acesso a insumos adequados (A08). A disponibilidade de serviços públicos de saúde sexual e reprodutiva para adolescente é baixa e pode estar ligada à subnotificação do HIV, pois a notificação compulsória dos casos de HIV passou a vigorar em 17 de fevereiro de 2016 pela portaria de número 204 do Ministério da Saúde (A05).

A iniciação precoce da atividade sexual dos adolescentes está associado diretamente aos aspectos: socioeconômicos e escolaridade. Quanto menor a renda e a escolarização mais cedo acontecerá a primeira relação sexual (A01). O baixo nível escolar aponta associação com a menor chance de uso do preservativo e a sexarca que, aliás, diminuiu no decorrer dos anos no Brasil (A05). O aspecto escolaridade tem influência direta no poder de discernimento e na tomada de decisões dos adolescentes quando estão diante de situações de risco (A08). O empobrecimento populacional é associado ao aumento de prevalência para faixa etária com maior incidência sobre mulheres que possuem baixa escolaridade e estão em situação de pobreza o que deixa claro que as desigualdades sociais são significantes para as condições de exposição dos adolescentes e torna-se importante para os riscos de contaminação do HIV/AIDS (A09).

Os determinantes sociais da saúde como: idade, escolaridade, gênero, status socioeconômico determinam o contexto que os adolescentes estão inseridos e consequentemente aos possíveis riscos de contaminação (A03). Outros fatores específicos encontrados para essa faixa etária que também são determinantes para os riscos de infecção são: a multiplicidade de parceiros, tatuagens e uso de piercing e drogas (A01). Essa série de fatores estruturais afetam os adolescentes, independentemente de sua vontade e isso requer adaptação na metodologia preventiva específica para esse extrato populacional (A08). Assim a literatura traz como proposta pensar a adolescência e a problemática desses fatores através do rompimento das práticas fragmentadoras em saúde e considerar não somente a influência do contexto, mas pensar o adolescente como um ser singular e integral (A11).

O uso do álcool e drogas antes das relações sexuais pelos adolescentes são dois aspectos importantes por que torna esse grupo mais propenso a infecção devido à diminuição do raciocínio, aumento do número de parceiros sexuais e do sentimento de invulnerabilidade (A01). É preocupante o número de adolescentes que mantém relações sexuais desprotegidas sob o efeito do álcool ou de alguma droga, eles acreditam que não podem contrair o vírus (A08). Além dos riscos que as relações desprotegidas podem causar aos adolescentes ainda 
tem o risco da dependência química a essas substâncias que também é um problema de saúde pública grave na sociedade.

Outros aspectos que estão sob a ótica dos autores é a violência influenciada pelas questões de gênero, ambos aspectos são vistos em apenas dois artigos o que representa 15,3\% da literatura revisada. As relações de poder mediada pelo gênero incube a mulher o papel de subserviência e isso acarreta na maioria das vezes na tomada de decisões nas relações pelo homem (A09). O modelo patriarcal machista faz parte da cultura brasileira e esse modelo proporciona ao homem o poder de decidir e provar sua virilidade assumindo a responsabilidade dos riscos sexuais, restando a mulher corresponder aos desejos masculinos. Essa situação deixa uma lacuna para a figura feminina ser vista e tratada como um ser submisso ao sexo masculino o que acarreta em alguns casos a violência doméstica e a exploração sexual.

A exploração sexual é mencionada em apenas um artigo da revisão o que corresponde a 7,6\%, é um tema pouco discutido mais bastante estratégico na prevenção do HIV. Esse aspecto ocorre muitas vezes pela necessidade da sobrevivência financeira dos adolescentes e especificamente os que vivem nas ruas por que não procuram os serviços de saúde e isto se deve ao medo de serem conduzidos a instituições de proteção (A10). O diálogo pode ser um instrumento que venha contribuir junto ao adolescente para detectar os casos de exploração e violência principalmente dentro da escola e da família (A06).

\section{CONCLUSÃO}

Ao pensar a prevenção da AIDS/HIV para adolescentes no Brasil também é preciso identificar quais aspectos dificultam essa prática. A prevenção da saúde a esse grupo é uma tarefa ampla e complexa que exige uma articulação do setor saúde com os demais setores da sociedade. De uma maneira sucinta a pesquisa revelou que a exposição ao risco de infecção pelo HIV é alta sendo uma resultante da soma de aspectos dificultadores e fatores sociais inter-relacionados.

A prevenção é um aspecto pouco discutido na literatura, a palavra prevenção é apenas colocada em seu sentido estrito. Os artigos não abordam a prevenção em um sentido amplo partindo desde a elaboração de políticas, planejamento, implementação de ações e estratégias de promoção, os autores tem uma maior preocupação em identificar problemas decorrentes da 
ausência de prevenção. Diante dessa problemática se constitui uma grande oportunidade para discutir e problematizar a prevenção de uma maneira mais abrangente operacionalizando-a com os demais aspectos encontrados.

Esse estudo tenta trazer uma pequena contribuição para a temática e sugere a necessidade de (re)pensar o modelo de prevenção para HIV/AIDS em adolescentes. Ainda existem aspectos ociosos de práticas estratégicas de enfrentamento, como: a exploração sexual, álcool e drogas, questões de gênero e a violência doméstica. Esse debate pode ganhar um maior espectro de importância se colocado em maior evidência no meio público, científico, midiático, social e religioso.

\section{REFERENCIAS}

ARAÚJO, T.M.E; Fatores de risco para infecção por HIV em adolescentes. Rev. Enferm. UERJ, Rio de Janeiro, 2012 abr/jun; 20(2):242-7.

CAMPOS, C.G.A.P. A vulnerabilidade ao HIV em adolescentes: estudo retrospectivo em um centro de testagem e aconselhamento. Rev. Min. Enferm. 2014 abr/jun; 18(2): 310-314.

CAVALCANTI, L.J. Adolescentes em acolhimento provisório: uma análise investigativa sobre a vulnerabilidade ao HIV. Fundam. Care. 2015. Abr./jun. 7(2): 2516-2525.

CERQUEIRA-SANTOS, E. et al. Gravidez na adolescência: análise contextual de risco eproteção. Psicol. estud., Maringá, 2010.

CHAVES, A.C.P. Conhecimentos e atitudes de adolescentes de uma escola pública sobre transmissão sexual do HIV. Rev. Bras. Enferm. 2014 jan-fev; 67(1):48-53.

CHEHTER, E.Z. Drogas antirretrovirais e pancreatite aguda em pacientes com HIV/AIDS. einstein. 2014;12(1):112-9.

COSTA, A.C.P.J. Vulnerabilidade de adolescentes escolares às DST/HIV, em Imperatriz Maranhão. Rev. Gaúcha Enferm. 2013; 34(3): 179-186.

FERREIRA, A.G.N. Cultura masculina e religiosidade na prevenção das DST/HIV/AIDS em adolescentes. Mineira Enferm.; 16(4): 572-578, out./dez., 2012.

GUBERT, F.A. Protagonismo de adolescentes na prevenção de doenças sexualmente transmissíveis. Acta Paul Enferm. 2015; 28(5): 482-7.

LEITE, Luciano; AMÉRICO, Carlos. Infecção por HIV passa ser de notificação compulsória. 2014. Disponível em: <http://www.aids.gov.br/noticia/2014/infeccao-por-hivpassa-ser-de-notificacao-compulsoria>. Acesso em: 15 abr. 2018. 
MINISTÉRIO DA SAÚDE. Secretária de Vigilância em Saúde. Departamento de DST, AIDS e Hepatites Virais. Boletim Epidemiológico- AIDS e DST. Brasília/DF, 2016. ISSN 1517 1159. Disponível em: <http://www.aids.gov.br/publicacao/2016/boletim-epidemiologico-deaids-2016>.

MOURA, L.R. The gap between knowledge on HIV/AIDS and sexual behavior: a study of teenagers in Vespasiano, Minas Gerais State, Brazil. Cad. Saúde Pública, Rio de Janeiro, 29(5): 10081018, mai., 2013.

OLIVEIRA CAMPOS M, et al., Contextual factors associated with sexual behavior among Brazilian adolescents. Annals of Epidemiology (2013), Available from: <http://dx.doi.org/10.1016/j.annepidem.2013.03.009>. Cited 2017, Apr. 22.

PATIAS, N.D.; DIAS, A.C.G. Sexarca, informação e uso de métodos contraceptivos: comparação entre adolescentes. PSICO-USF, Itatiba, v.19, n.1, p.13-22, jan./abr. 2014.

PRADO, C.C. Conhecimento de estudantes adolescentes sobre transmissão, prevenção e comportamentos de risco em relação as DST/HIV/AIDS. Fundam. Care. 2016. Out/dez. 8(4): 5054-5061

RIBEIRO, L.V. Saúde sexual de adolescentes institucionalizadas: contribuições da enfermagem na perspectiva da Teoria do Modelo de Promoção da Saúde de Nola Pender. 2015. 200 f. Dissertação (Mestrado em Enfermagem) - Faculdade de Enfermagem. Universidade do Estado do Rio de Janeiro, Rio de Janeiro, 2015.

ROEHRS, Hellen. Adolescência na percepção de professores do ensino fundamental. São Paulo, Rev. Esc. Enferm. USP 2010; 44(2):421-8.

SAITO, M.I. Educação sexual na escola. Rev. Pediatria (São Paulo) 2000, 22(1): 44-48.

SILVA, A.F. O adolescente brasileiro e as razões do não uso do preservativo para prevenção do HIV/Aids. Rev. Enferm. UFPI. 2015, jan-mar; 4(1): 106-10.

SILVA, I.R. Percepções de enfermeiros acerca das vulnerabilidades para DST/Aids diante das conexões do processo de adolescer. Rev. Gaúcha Enferm. 2015 set;36(3):72-8.

SILVA, R.I. O pensamento complexo subsidiando estratégias de cuidados para a prevenção das DST/AIDS na adolescência. Texto Contexto enferm. Florianópolis, 2015 jul-set; 24(3):859-66

SOUSA, A.I.A. Uso da carga viral e de técnicas de georreferenciamento como contribuição para o monitoramento da transmissão de HIV/AIDS no Brasil, 1996 a 2011. Dissertação de Mestrado (mestrado em 2014). Núcleo de Medicina Tropical, Universidade de Brasília, Brasília, 2014. Disponível em: <http://repositorio.unb.br/bitstream/10482/17148/1/2014_ArturIuriAlvesDeSousa.pdf>. Acesso em: 7 abr. 2017.

TAQUETTE, S.R. Epidemia de HIV/AIDS em adolescentes no Brasil e na França: semelhanças e diferenças. Saúde Soc. São Paulo, v.22, n.2, p.618-628, 2013. 
URSI ES, Galvão CM. Prevenção de lesões de pele no perioperatório: revisão integrativa da literatura. Rev Latino-am Enfermagem 2006 janeiro-fevereiro; 14(1):124-31.

VIEIRA, N.F.C. Dialogando com adolescentes de grupos religiosos sobre HIV: desafios para a enfermagem. Texto Contexto Enferm., Florianópolis, 2013 Out-Dez; 22(4): 952-60.

WHITTEMORE R. Combining evidence in nursingresearch: methods and implications. Nurs Res. 2005Jan-Feb; 54(1):56-62

World Health Organization.Health issues:Adolescent Health [internet]. WHO; 2017. Available from:<http://www.who.int/topics/adolescent_health/es/>. [cited 2017 Apr. 02].

World Health Organization. Healt issues: VIH/SIDA [internet]. WHO; 2017. Available from:<http://www.who.int/topics/hiv_aids/es/>. [cited 2017 Apr. 04].

World Health Organization.Health issues:Lidar con el VIH en la adolescencia [internet]. WHO; 2017. Available from:<http://www.who.int/features/2013/adolescents-hiv/es/>. [cited 2017 Apr. 05]. 


\section{APÊNDICES}

\section{APÊNDICE A - PERCENTUAL DOS ASPECTOS}

\begin{tabular}{|c|c|c|}
\hline ASPECTO & CÓDIGOS & PERCENTUAL \\
\hline EDUCAÇÃO & $\begin{array}{c}\mathrm{A} 01, \mathrm{~A} 02, \mathrm{~A} 03, \mathrm{~A} 04, \mathrm{~A} 05, \\
\mathrm{~A} 06, \mathrm{~A} 07, \mathrm{~A} 08, \mathrm{~A} 09, \mathrm{~A} 10 \mathrm{e} \\
\mathrm{A} 12 .\end{array}$ & $\begin{array}{c}11 \text { Artigos } \\
84,6 \%\end{array}$ \\
\hline CONHECIMENTO & $\begin{array}{l}\text { A01, A03, A04, A05, A06, } \\
\text { A07, A09, A10, A12 e A13. }\end{array}$ & $\begin{array}{c}10 \text { Artigos } \\
76,9 \%\end{array}$ \\
\hline PRESERVATIVO & $\begin{array}{l}\text { A01, A02, A03, A04, A05, } \\
\text { A06, A08, A10, A12 e A13. }\end{array}$ & $\begin{array}{c}10 \text { Artigos } \\
76,9 \%\end{array}$ \\
\hline PREVENÇÃO & A04, A06, A07, A08 e A13. & $\begin{array}{l}5 \text { Artigos } \\
38,4 \%\end{array}$ \\
\hline VULNERABILIDADE & A01, A04, A05 e A08. & $\begin{array}{c}4 \text { Artigos } \\
30,7 \%\end{array}$ \\
\hline AUTONOMIA & A02, A09, A11 e A12. & $\begin{array}{l}4 \text { Artigos } \\
30,7 \%\end{array}$ \\
\hline INVESTIMENTO & A01, A05 e A09. & $\begin{array}{l}3 \text { Artigos } \\
23,07 \%\end{array}$ \\
\hline PRECOCE & A01, A03 e A07. & $\begin{array}{l}3 \text { Artigos } \\
23,07 \%\end{array}$ \\
\hline $\begin{array}{l}\text { DETERMINANTES } \\
\text { SOCIAIS }\end{array}$ & A03, A04 e A08. & $\begin{array}{l}3 \text { Artigos } \\
23,07 \%\end{array}$ \\
\hline ACESSO AO SUS & A05, A08 e A10. & $\begin{array}{l}3 \text { Artigos } \\
23,07 \%\end{array}$ \\
\hline SOCIOECONÔMICO & A01 e A09. & $\begin{array}{c}2 \text { Artigos } \\
15,3 \%\end{array}$ \\
\hline INTEGRALIDADE & A01 e A11. & $\begin{array}{c}2 \text { Artigos } \\
15,3 \%\end{array}$ \\
\hline
\end{tabular}




\begin{tabular}{ccc}
\hline ASPECTO & CÓDIGOS & PERCENTUAL \\
\hline ALCOOL e DROGAS & A01 e A08. & 2 Artigos \\
\hline CULTURA e GÊNERO & A02 e A09. & $15,3 \%$ \\
\hline ESCOLARIDADE & A05 e A08. Artigos \\
\hline EXPLORAÇÃO SEXUAL & $15,3 \%$ \\
\hline DIÁLOGO & A10. Artigos \\
\hline & & $15,3 \%$ \\
\hline
\end{tabular}

